\title{
Arquivo e política: transição e heterotopias constitucionais
}

\author{
Archive and politics: constitutional transition and heterotopias \\ Archivo y política: transición y heterotopías constitucionales
}

Murilo Duarte Costa Corrêa ${ }^{*}$

\section{Resumo}

A Constituição de 1988 não deveria ser pensada como um documento que selaria a passagem da ditadura à democracia no Brasil. De Carl Schmitt a Giorgio Agamben, a teoria do Estado de exceção e sua crítica contribuíram para tornar visível a abscôndita indistinção entre Estado de direito e Estado de exceção. Uma constituição que se sucede a um período de exceção tanto o continua sob novos termos quanto encerra o gérmen para rupturas locais com o passado autoritário que insiste em repetir. Demonstrando algumas dessas relações de continuidade-ruptura na literatura sobre a transição política brasileira, este artigo propõe repensar a Constituição de 1988 a partir da categoria de arquivo, explorando-a no contágio recíproco entre as obras de Michel Foucault e Jacques Derrida. Isso permite desenvolver como saí- da política possível a relação entre uma política de arquivo e a prática de uma heterotopia constitucional.

Palavras-chave: Arquivo. Constituição. Política.

\section{Trinta anos depois}

Nas últimas décadas, a constituição da memória na transição brasileira adquiriu destacada relevância e atualidade. A produção institucional da verdade e os instrumen-

Doutor em Filosofia e Teoria Geral do Direito pela Universidade de São Paulo. Professor adjunto, Departamento de Direito de Estado, Programa de Pós-Graduação em Ciências Sociais Aplicadas (Mestrado e Doutorado), Universidade Estadual de Ponta Grossa. E-mail: murilodccorrea@ gmail.com

Recebido em 15/5/2018 - Aprovado em 12/6/2018 http://dx.doi.org/10.5335/hdtv.18n.3.8592 
tos que regulam o acesso a documentos relacionados à construção da memória coletiva (HALBWACHS, 1997) tornaram-se campos privilegiados de disputas simbólicas, e as diversas instâncias institucionais de produção da memória passaram a figurar no centro de alguns dos principais embates políticos do presente.

A literatura sobre a transição política brasileira a qualifica como uma experiência essencialmente conservadora. Como sustentou, entre muitos, Gilberto Bercovici (2010, p. 77-90), a transição democrática no Brasil teria se realizado à custa da continuidade local de funcionamentos autoritários no interior de instituições formalmente democráticas e da extorsão política do perdão institucional aos agentes de Estado violadores de direitos humanos. Por isso, Paulo Sérgio Pinheiro (2010, p. 09-14), Edson Teles (2010, p. 299-318) e Paulo Ribeiro da Cunha (2010, p. 15-40) afirmaram que o Estado democrático de direito no Brasil é marcado pela persistência de estruturas burocrático-administrativas ditatoriais. Essa conservação institucional desafia o enigma das relações entre legalidade e autoritarismo e impõe as tarefas de cartografar os arcanos autoritários que insistem no interior do Estado de direito e de detectar as condições de possibilidade de sua maquinal eficácia.

Estar à altura dessa tarefa exige revolver uma série de apagamentos e funcionamentos, entre eles os que a própria Constituição de 1988 implica. Não é suficiente afirmar incansavelmente a existência de uma duradoura crise constitucional, marcada por sua visível inefetividade; esta seria uma denúncia politicamente vazia, caracte- rística do senso comum teórico de juristas progressistas e de um novo constitucionalismo que se subtrai à história constitucional, como Lynch e Mendonça (2017, p. 980) demonstraram. Tampouco bastaria reafirmar a deontologia dos enunciados constitucionais diante de práticas judiciais que resultam na institucionalizada neutralização de sua normatividade democrática (MATOS; SOUZA, 2017, p. 303).

Seria necessário repensar a Constituição deslocando a condição triunfal de documento/monumento que promove a redemocratização ao mesmo tempo em que suspende uma série de seus próprios efeitos. Essa disparidade entre sua pulsão democrática e sua ineficácia local e estratégica exige colocar em questão as funções documentais e monumentais da Constituição de 1988. Para tanto, este artigo propõe repensá-la como arquivo, explorando as relações de proximidade e distância desse conceito nas obras de Michel Foucault e Jacques Derrida. Esse gesto analítico permite iluminar as condições que tornam possível uma íntima e paradoxal coerência entre um regime de visibilidades constitucionais, ligadas a uma transição inconclusa, e um regime de enunciabilidades constitucionais, ligadas a uma redemocratização em suspenso. É em função dessa articulação díspar, tornada eficaz e coerente, que se pode afirmar que a Constituição é um arquivo da exceção. Isso talvez baste para superar o senso comum teórico e politicamente inofensivo que se satisfaz em apontar as inefetividades da Constituição ou em praticar um positivismo de combate que permanece condicionado pelo a priori histórico que contém seus efeitos democráticos. 
Todavia, pensada como lugar de inscrição em que se exerce um poder de consignação (reunião de signos e atribuição de sentido), a função-arquivo da Constituição deixa entrever a possibilidade de outros arranjos histórico-políticos. Isto é, sua condição mesma de arquivo da exceção envolve uma potência para que a Constituição possa constituir a sede de uma outra política de arquivo, ou do que preferimos chamar de uma heterotopia constitucional, que destitua a exclusividade do princípio arcôntico (o exercício oligárquico da interpretação e da jurisdição sobre o seu arquivo).

\section{Direito, transição e constituição}

Não é raro que os novos constitucionalistas brasileiros representem a Constituição de 1988 como um "marco zero" democráti$\mathrm{co}$, a origem puntiforme de uma "nova história" constitucional (BARROSO; BARCELLOS, 2003, p. 142). Essa postura destina toda uma história constitucional com quase dois séculos de duração - que, afinal, confunde-se com a história do Estado brasileiro - à condição de uma esmaecida "pré-história", apagando de sua genealogia o fato de que nosso "constitucionalismo inacabado" erigiu-se sobre ruínas coloniais (BONAVIDES, 2000, p. 155-156) e escravistas, e se desenvolveu segundo a persistência de uma lacuna democrática própria de países governados por elites oligárquicas (BONAVIDES, 2003, p. 382). Também torna invisível que parte significativa do discurso e da experiência constitucionais no Brasil ocorrera sob o signo da exceção (CÂMARA; MOREIRA, 2017, p. 217, 235), não raro confundindo-se com as multiformes operações de suspensão da ordem constitucional para manter a integridade da própria ordem.

Pesquisar essa genealogia não implica fazer do presente, e dos instrumentos democráticos que passam a exigir consolidação especialmente após 1988, tabula rasa do passado, lançando o presente e o passado a uma completa indiferença. Trata-se de assumir a tarefa de tornar sensíveis as condições que tornam possível que legados antidemocráticos se reproduzam e se dissimulem quotidianamente em um corpus constitucional pretensamente democrático. A presença de um legado autoritário constitui o índice de incompletude do processo de transição democrática atestado entre nós já há alguns decênios (PINHEIRO, 2002, p. 240-242; ABRÃO; TORELLY, 2011, p. 241).

Ainda que seja "a melhor das constituições" (BONAVIDES, 2000, p. 174), desde sua edição, a Constituição de 1988 não deixou de sofrer ataques ao seu viés social, seja por via de revisão, de reformas constitucionais ou da normalização institucional e judiciária de sua ineficácia (BONAVIDES, 2003, p. 371; CARVALHO, 2015, p. 208-218). Para lançar luz sobre as mais recentes "regressões" constitucionais em matéria de direitos de cidadania, bem como da atuação do Estado brasileiro pós-ajustes neoliberais que teriam conduzido todo o plexo de direitos sociais a um patamar pré-1988 (FAGNANI, 2015), seria necessário compreender as genealogias que os discursos constitucionais redentores apagam e o efetivo papel político que as constituições desempenham.

Organizadas ao redor ora da conservação da memória, ora de sua codificação, 
as regulações institucionais da memória não raro engendram operações paradoxais. De um lado, dispositivos vinculados aos direitos humanos procuram conservá-la; de outro, muitas vezes, só podem conservá-la cedendo as operações de transcrição e sobrecodificação que sofrem no interior de aparatos fundados na violência do Estado, concretizada em instituições que constituem os objetos desses mesmos direitos, e instituem Comissões de Anistia, políticas reparatórias, regram o acesso a informações e a política de arquivos, procuram esclarecer a verdade histórica. Eis o que está em jogo na dimensão representativa que instituições e escritura histórica instauram, e que torna necessário interrogar.

Embora se reconheça, frequentemente, a constitutividade recíproca entre direito, transição institucional e elaboração da memória (SANTOS, 2009, p. 476), é raro que o próprio direito, como disciplina de regulação, seja compreendido como instância de registro, codificação e produção da memória coletiva. A perpétua crise da Constituição de 1988 deveria servir de alerta, em especial aos juristas, de que toda constituição contém (no duplo sentido de envolver e refrear) as dimensões do documento/monumento, do arquivo e da memória. Isso talvez permitisse interpretar o direito não como um conjunto de prescrições comportamentais positivas, mas como "escrivão da memória social" (OST, 2001, p. 88-89). Assim, o direito e suas instituições surgiriam como operadores da elaboração cultural do tempo, e suas técnicas seriam efeitos das relações de força e jogos de poder (OST, 2001, p. 26-27) que, muitas vezes, permanecem irrepresentáveis.
Seria o caso de questionar a real função política que a Constituição de 1988, mas também os discursos constitucionais redentores que a secundam, exerce em relação às tarefas de uma transição política e democrática que permanece inacabada. É preciso pensar a Constituição de 1988 a partir de suas fontes político-normativas: a Lei Federal no 6.683/1979 e a Emenda Constitucional $n^{\circ} 26 / 1985$. Não porque estas a maculem com um vício de origem, mas porque, sendo a exceção que a Constituição arquiva, essa perspectiva permite uma aproximação dos funcionamentos que tornam possível a convivência entre uma ordem normativamente democrática e a constância das operações autoritárias e neoliberais, que tendem a neutralizar seus efeitos transicionais.

Seguindo as lições de Jacques Le Goff (2012, p. 521-522), é imprescindível criticar a Constituição como documento, revelando-o como "resultado de uma montagem" social, política e histórica; como "monumento" ou texto essencialmente desmontável por uma multiplicidade de técnicas críticas que permitiriam explicar a filiação entre os aparentes avanços democráticos e sociais que a Constituição de 1988 implicou e sua persistente neutralização institucional, que normaliza sua ineficácia como regra. Isso implica compreender a Constituição a partir de sua função de arquivo.

Ao invés de tratar a Constituição de 1988 como um documento, um conjunto de textos ou normas de direito positivo, ou como monumento, uma montagem social, política e histórica, seria preciso captar sua efetiva função política no cruzamento desses dois conceitos; na sua dupla condição de 
"monumento documental" e de "documento monumental". A Constituição designa tanto o monumento que resulta de uma montagem social, política e histórica como o documento positivo, visível como texto e imagem, e enunciável como promessa e futuro. Isso requer a articulação entre a Constituição e a formação histórica a que ela corresponde, bem como o regime de sensibilidades de que ela participa, iluminando seu persistente e paradoxal déficit de efetividade.

\section{Arquivar a exceção}

Como em alguns dos trabalhos mais célebres de René Magritte - e.g., La trahison des images (1929), ou Les mots et les images (1929) -, em que o figurativo e o discursivo estão agenciados segundo uma desconformidade essencial (FOUCAULT, 2001, p. 670), a Constituição é um agenciamento histórica e pragmaticamente variável de suas funções de "documento monumental" e "monumento documental"; isto é, supõe uma ordem do ver e do dizer que não se confundem nem com o que se vê, nem com o que se diz. Isso significa que tudo o que se pode ver (o visível) e tudo o que se pode dizer (o dizível) estão sustentados previamente por uma ordem que os disciplina. Para dizê-lo em uma palavra, seria preciso tratar a Constituição como arquivo, a partir das condições a priori dadas em função de um agenciamento das visibilidades e dos enunciados que remete a uma formação histórica determinada e, nos termos de Foucault (2010b, p. 147), corresponde a um regime de verdade.

Se, de um modo, a Constituição de 1988 é representada como o documento que instaurou a redemocratização no Brasil pós-ditadura, paradoxalmente, ela permanece o monumento que torna coerente a relação entre a continuidade de práticas autoritárias e violadoras de direitos humanos e a nova ordem constitucional. Por isso, Kathryn Sikkink e Carrie Booth Walling (2007, p. 437) reconheceram a exemplaridade da transição brasileira ao afirmarem que a transição democrática é uma causa necessária, mas não suficiente, para o aperfeiçoamento das práticas estatais e sociais relacionadas a direitos humanos.

A transição conservadora no Brasil baseou-se em consensos fortemente arraigados nas instituições, que embaraçaram a possibilidade de reformas e reproduziram a lógica político-jurídica própria do período de exceção, que coincide com a perpetuação de práticas de legalidade autoritária (PEREIRA, 2010, p. 283-294). Após a transição para o regime democrático, os aparelhos de controle social e repressão estatais não serão desmontados, não sofrerão purgas, nem serão reestruturados pelo Estado brasileiro. $\mathrm{O}$ aparato de violência legal, em pleno funcionamento (INSTITUTO DE PESQUISA ECONÔMICA APLICADA; FÓRUM BRASILEIRO DE SEGURANÇA PÚBLICA, 2017, p. 55), permanece atrelado a estruturas e práticas institucionais herdadas do regime de exceção, o que poderia elucidar, ao menos em parte, a escalada da violência discursivamente naturalizada como endêmica no Brasil pós-ditadura (PINHEIRO, 2002, p. 240).

Como explicar que uma ordem do visível, que se confunde com a sobrevivência de instituições, estruturas autoritárias e práticas sistematicamente violadoras de direitos 
humanos, ou amesquinhadoras de direitos sociais, possa conviver coerentemente com uma ordem do enunciável, que se confunde com o corpus constitucional e sua discursividade democrática? De que maneira pensar a Constituição de 1988 como arquivo torna possível compreender as relações de continuidade-ruptura que não cessaram de se reproduzir paradoxalmente na vigência da Constituição cidadã? Na medida em que a noção de arquivo remete à formação histórica que constitui o a priori em que o conjunto de práticas democraticamente deficitárias se reproduzem. Eis o que torna possível compreender tanto o nexo aparentemente coerente entre visibilidades inconstitucionais e enunciados constitucionais como cerne operativo de sua efetiva função política.

Para tanto, é preciso ultrapassar a definição tradicional de arquivo como um locus físico que abriga rastros documentais e escritos interpretáveis (RICCEUR, 2007, p. 177), lendo os discursos que lhes concernem imediatamente como monumentos (CASTRO, 2014, p. 78). Nessas condições, a Constituição de 1988 pode ser vista como uma fita de dupla face, que articula a um só tempo o elemento visível de uma transição inconclusa, quotidianamente manifestada em práticas sociais e estatais violadoras de direitos humanos, e o elemento enunciável de um texto positivo que pretende inaugurar uma tradição democrática. Para que essa articulação seja possível, a Constituição supõe o seu arquivo, isto é, a combinação do visível e do enunciável que torna essa articulação paradoxal coerente como sua "condição de realidade" (FOUCAULT, 2010b, p. 144). Porém, em que sentido se pode dizer que a Constituição arquiva a exceção?
Um dos postulados de Foucault consiste em afirmar que cada formação histórica se define por um regime em si mesmo histórico e transformável que combina o visível e o enunciável sob a forma da sua mútua irredutibilidade (DELEUZE, 2013, p. 33). Os saberes correspondem a formas de arranjar visibilidades e enunciabilidades, mantidas separadas e, ao mesmo tempo, conjugadas sob a condição de sua heterogeneidade irredutível. Toda experiência se efetua segundo os limites traçados por seu a priori histórico, seu arquivo, e pelo específico regime de verdade que estes instauram como condição do ver e do dizer. Não pode haver, nesse sentido, "experiência selvagem", independente desses condicionamentos. Toda experiência do visível e do dizível é recortada por suas condições, mas, diferente do que se passa com a crítica kantiana, em Foucault, essas condições correspondem ao a priori histórico, o arquivo, o dispositivo que é o traço de união-distinção entre o ver e o falar.

Uma época vê tudo o que se pode ver e diz tudo o que se pode enunciar, mas apenas na medida em que o a priori histórico condiciona, impõe os limites do visível e do enunciável (FOUCAULT, 2010b, p. 148), e regula as leis de sua transformação. Portanto, tudo o que se vê e se diz é da ordem das evidências. Não há nada a descobrir sob a superfície luminosa das imagens ou sob a tagarelice das palavras que a Constituição envolve,

[...] que por detrás da cortina nada há para ver, mas [para Foucault] tanto mais importante era descrever a cada momento a cortina, a base, visto que nada existe por detrás ou por debaixo (DELEUZE, 1986, p. 61). 
O que é preciso pesquisar não é o que a Constituição permite ver ou dizer, ou a evidente fratura entre o que se vê e o que se diz (suas evidências), mas como ela dá a ver o que permanece visível e como ela torna enunciável o que ela faz dizer; isto é, a condição urgente e própria à nossa atualidade. Sob que condições uma transição política inconclusa pode corresponder a uma ordem de visibilidades díspar e, ainda assim, estranhamente associada à ruptura democrática que a Constituição de 1988 instaura no nível dos discursos? Como ela assegura uma tranquila e bizarra unidade coerente entre as promessas de ruptura democrática que a Constituição instaura no registro dos enunciados e dos discursos e a continuidade de práticas, instituições, estruturas violadoras de direitos humanos, aparentadas ao período de exceção brasileiro?

Sob o clássico e insustentável paradoxo do poder constituinte, que ora constitui um "poder que surge do nada e organiza o direito", ora deve ser reduzido à norma internalizada de sua produção (NEGRI, 2015, p. 02-03), ou sob o "fundamento místico da autoridade" (DERRIDA, 2007, p. 25), é preciso reencontrar o real do arquivo. $\mathrm{O}$ que a Constituição arquiva como condição do agenciamento paradoxal que define seu $a$ priori histórico é a exceção, como fundamento e lógica operativa. Não apenas porque a origem da Constituição de 1988 poderia ser encontrada nos dispositivos anistiadores da Lei Federal $n^{\circ} 6.683 / 1979$, repetidos na Emenda Constitucional no 26/1985 - o mesmo ato normativo que convocou a Assembleia Nacional Constituinte que deu origem à Constituição democrática de 1988; mas porque é uma relação de exceptio, de captura em uma região de exterioridade (AGAMBEN, 2007, p. 25), aquela que permite articular coerentemente a ordem das visibilidades e das enunciabilidades constitucionais.

Os déficits transacionais e democráticos, aferíveis em qualquer relatório sobre o estado dos direitos humanos no Brasil produzido nas últimas três décadas, constituem o elemento de visibilidade que se mantém irredutível aos enunciados e às práticas discursivas constitucionais, ora porque estas os contornam e neutralizam, ora porque os chancelam. Sob a lógica da disjunção e da desconformidade entre ambos, o visível não cessa de capturar o enunciável - como na denúncia tão contumaz quanto vazia da inefetividade da Constituição -, e o enunciável não cessa de capturar o visível - como na afirmação naïf de sua força normativa.

A Constituição de 1988 funciona como um dispositivo de arquivamento da exceção na medida em que, por meio da manutenção de uma unidade coerente, heterogênea e distinta, ela agencia os avatares de uma transição inconclusa a uma série de promessas normativas que permanecem indiferentes ao real. Dessa forma, transição e exceção coincidem, não como a mera suspensão da eficácia de uma ordem jurídica que se mantém, no entanto, válida, mas como condição arquivística de que essa unidade desconforme é o efeito visível ou enunciável. Assim, a Constituição de 1988 não deixa de representar uma ruptura democrática, mas esta é efetuada na medida de sua suspensão. Paradoxalmente, ela permanece suspensa ao se realizar, e se realiza ao permanecer em suspenso. $\mathrm{O}$ direito, como técnica social e normativa, por 
implicar uma cisão entre os registros do normativo e do empírico, torna-se então uma tecnologia apropriada à função de arquivar a exceção que as Constituições - mesmo as mais democráticas - desempenham.

\section{Arquivo e política}

$\mathrm{O}$ arquivo não remete ao passado ou ao tempo perdido, mas à constituição de um lugar de autoridade (DERRIDA, 2001, p. 08), à instauração de uma topologia e a uma técnica de consignação como condições do arquivo. $\mathrm{O}$ arquivo induz tanto a um lugar arquivístico como a uma autoridade que o institui como tal. Em Foucault, o arquivo se confunde com a própria condição de realidade que ordena o visível e do enunciável. Apesar de todas as distâncias para com a noção foucaultiana de arquivo, a démarche derridiana, ao remeter o arquivo à noção de autoridade, permite superar a vagueza de sua presença pressuposta na noção de uma ordem do visível e do enunciável, sem que seja preciso passar a uma analítica do poder.

A raiz etimológica da palavra "arquivo" deriva do grego antigo arkhê, termo que designa a um só tempo começo ou princípio em sentido natural e histórico, e comando, espaço ou ordem social em que se exerce a autoridade (DERRIDA, 2001, p. 11). Arquivo é um termo que pode ser tomado simultaneamente em sentido físico, histórico ou ontológico e no sentido nomológico de comando, indicando a articulação e a sincronia de uma oposição clássica entre os gregos: a oposição entre phúsis e nomos, ontologia e nomologia. Arkheiôn indicava, ainda, um logradouro e uma topologia em que se exercia a autoridade: o endereço e a casa dos arcontes, magistrados superiores encarregados de comandar, interpretando a lei com exclusividade e conservando arquivos (DERRIDA, 2001, p. 12-13).

No entanto, a função árquica não se exerce somente em um cruzamento entre topologia e nomologia; é necessário que a autoridade arcôntica caminhe junto com um poder de consignar os signos, reunindo-os. O poder de consignação "[...] tende a coordenar um único corpus em um sistema ou uma sincronia na qual todos os elementos articulam a unidade de uma configuração ideal" (DERRIDA, 2001, p. 14). Portanto, assim como Foucault (2010a, p. 10) descobrirá, pouco tempo depois de sua Arqueologia do saber, o poder subjacente - esse dispositivo que estabelece uma partilha entre o visível e o enunciável e implica uma ordem -, o poder de consignação derridiano propõe imediatamente a ideia de que sob o arquivo se encontram uma ordem, um princípio de autoridade e, portanto, uma linha de fuga política.

O exercício do poder arcôntico fazia dos mais altos magistrados gregos os depositários responsáveis pela segurança física dos suportes arquivísticos. Seus domicílios conservavam os arquivos sobre os quais se exerciam os direitos de interpretá-los e de dizer a lei, de hermenêutica e jurisdição. Ao desempenharem a guarda física e hermenêutica dos arquivos, a função arcôntica implicava um regime de visibilidades e enunciabilidades, um nomos e uma ordem da autoridade segundo a qual o lugar dos arquivos e o seu sentido interpretável podiam ser situados. 
Uma política do arquivo precede o seu ser. Todo arquivo implica uma política sob a sua nomologia, sob determinada lógica de comando, que instaura e assinala o lugar do começo ou do princípio. Em paralelo, uma ordem do visível e do enunciável forja um regime em que visibilidades e enunciados se articulam sem se confundir, segundo a noção foucaultiana de arquivo, como se só o nomos pudesse ser mais profundo que a phúsis; como se mais profundo que o ser, só a política que assegura a reunião de seus elementos segundo uma ordem singular, erigida a partir do que Derrida chamou de poder de consignação.

Tracemos um eixo imaginário entre Foucault e Derrida. Assim como o arquivo se define em Foucault pela heterogeneidade irredutível, pela articulação discordante, entre o visível e o enunciável, o arquivo, em Derrida, implica o agenciamento contraditório entre o começo e o comando, a ontologia e a nomologia, a phúsis e o nomos. No entanto, enquanto o arquivo foucaultiano é a condição subjacente a essa articulação, no arquivo derridiano, esse nexo é função do exercício do poder de consignação ou do princípio arcôntico. Enquanto o traço mais claro do arquivo foucaultiano é o desacordo entre as ordens do visível e do enunciável uma dissipação cuja coerência só poderá ser recomposta por uma ciência arqueológica dos arquivos -, o traço distintivo da arquivística derridiana é a sincronia que, apesar de toda contradição e heterogeneidade, reúne todos os elementos arquivados, operada pelo poder de consignação. Dissipação sincrônica em Foucault e sincronia dissipativa em Derrida, ligadas em última análise por um elemento de saber-poder, seja uma arqueologia dos enunciados que descobre como sua condição uma ordem do arquivo, seja o exercício de um poder arcôntico exclusivo de conservar, consignar, reunir, interpretar, jurisdizer.

A autoridade, aparentemente, é o termo que permite articular as noções de arquivo e de direito. Não é por outra razão que Derrida insiste na desconstrutibilidade do direito e do arquivo, assim como da história de sua lei. Talvez por isso Derrida julgue capital que uma teoria do arquivo inclua "[...] a teoria [de sua] institucionalização, [...] da lei que aí se inscreve e do direito que a autoriza" (DERRIDA, 2001, p. 14).

Nesses termos, interpretar a Constituição como arquivo, percebendo que o que ela arquiva é a exceção que articula e separa ordens heterogêneas (visível e dizível, começo e comando, phúsis e nomos), implica abri-la à dimensão radicalmente política que preside a discordante coerência entre seus enunciados democráticos e todo um conjunto de visibilidades autoritárias. Trata-se de compreender a Constituição como lugar da autoridade sob as condições de um poder de consignação ou de uma formação histórica determinada; a Constituição em seu duplo estatuto de promessa fracassada e fracasso prometido. No entanto, deve-se levar a sério o alerta que Jacques Derrida faz ao afirmar que a condição de desconstrutibilidade do direito (e do arquivo, adicionemos) não é uma infelicidade: "Pode-se mesmo encontrar nisso a chance política de todo progresso histórico" (DERRIDA, 2007, p. 14). Isso deriva tanto do fato de o direito fundar-se sobre camadas textuais interpretáveis, trans- 
formáveis, com uma história própria, quanto do fato de seu fundamento último ser não fundado (DERRIDA, 2007, p. 26).

\section{Heterotopias constitucionais}

A luta democrática de nosso tempo não deveria, pois, limitar-se aos enunciados constitucionais, ou à disputa sobre os discursos que neutralizam sua eficácia original. A luta democrática de nosso tempo define-se como uma luta pelo arquivo e pela composição de condições sociais que permitam um exercício radicalmente democrático do poder arcôntico: uma espécie de anarquivismo político.

A luta política de nosso tempo não se confunde com uma simples política de abertura de arquivos do período de exceção. Ela deve ser isso, mas precisa ser mais que isso. Se ver e falar são as condições dos comportamentos e da mentalidade de uma época, é nos interessando pelos seus condicionamentos - isto é, pelo arquivo que remete a uma determinada formação histórica - que se pode fazer política. Isso é o mesmo que ultrapassar a história mesma para chegar a suas condições mais elevadas, ao princípio anarcôntico de seus devires.

Em um curso sobre Foucault, Gilles Deleuze (2013, p. 20-21) não cessou de insistir sobre a obsessão que Foucault tinha pelos espaços arquitetônicos e pela pintura, porque ambos implicam uma forma especial de dirigir a luz e, portanto, de instaurar um regime do visível. Quando Derrida insiste sobre a dimensão topológica dos arquivos é porque o lugar implica a palavra de ordem da autoridade, o exercício do princípio arcôntico e do poder de consignação. Essas duas apreensões heterogêneas da dimensão espacial a que o arquivo remete poderiam ser o início para pensar uma outra política de arquivo e uma nova luta pela Constituição, que só poderia agenciar-se nos termos de uma nova formação histórica.

Uma política de arquivo precisa ser capaz de instaurar um contraespaço; permitir experimentações constitucionais como o lugar de uma utopia situada, que desterra o espaço quadriculado, disciplinado, que define o regime de luz e sombra em que se produzem suas visibilidades e enunciabilidades autoritárias. Essa heterotopia, esse "espaço absolutamente outro" de que falou Foucault (2013, p. 21), deve poder ser justaposto a espaços com ele incompatíveis (FOUCAULT, 2013, p. 24), como um espaço de aberta contestação transformadora da formação histórica existente.

No entanto, essa heterotopia constitucional como política de arquivo não pode nascer desatrelada de uma radical destituição do privilégio do princípio arcôntico e de uma horizontalização do poder de consignação. A transição política brasileira só estará completa quando a exceção que a Constituição de 1988 arquiva for radicalmente contestada por uma política anarcôntica, pela progressiva construção de novas condições sociais e institucionais, que destituam a exclusividade dos poderes de consignação, interpretação e jurisdição dos juízes, transformando tanto a jurisprudência como a Constituição em categorias práticas do social.

A política de arquivo atravessa a totalidade do campo da política, de modo que 
"A democratização efetiva se mede sempre por este critério essencial: a participação e o acesso ao arquivo, à sua constituição e à sua interpretação" (DERRIDA, 2001, p. 16). Nessa medida, transição democrática, política de arquivo e a produção coletiva e experimental de heterotopias constitucionais se confundem ao infinito. Acessar o arquivo como lugar de autoridade, contribuir para sua constituição, participar de sua formulação, desterrar o lugar de que emana o nomos ou a ordem são, hoje, as condições necessárias para introduzir novas repartições nas ordens do visível e do enunciável constitucionais, com potência para suscitar os devires de uma nova formação histórica.

\section{Abstract}

The Brazilian Constitution of 1988 should not be represented as a document simply allowing Brazil's political transition to democracy. The state of emergency theories and its critics, from Carl Schmitt to Giorgio Agamben, put into light the unapparent nexus between the rule of Law and the state of exception. The constitution following a post-authoritarian scenario is a half-way stage between the new democratic and the previous regimes. This paper presents some of those permanence-rupture phenomena reviewing the Brazilian literature on transitional justice and approaches the Brazilian Constitution of 1988 through the concept of archive. The new approach is proposed exploring the idea of archive in Michel Foucault's and Jacques Derrida's philosophical works, enhancing the link between a politics of archiving and the practice of a constitutional heterotopy as a potential political exit.

Keywords: Archive. Constitution. Politics.

\section{Resumen}

La Constitución de 1988 no debería ser pensada como un documento que sellaría el paso de la dictadura a la democracia en Brasil. De Carl Schmitt a Giorgio Agamben, la teoría del estado de excepción y su crítica contribuyeron a hacer visible la abscisa indistinción entre estado de derecho y estado de excepción. Una constitución que se sucede a un período de excepción tanto lo continúa bajo nuevos términos cuanto que encierra el germen para rupturas locales con el pasado autoritario que insiste en repetir. En este artículo se propone repensar la Constitución de 1988 a partir de la categoría de archivo, explorándola en el contagio recíproco entre las obras de Michel Foucault y Jacques Derrida, demostrando algunas de esas relaciones de continuidad-ruptura en la literatura sobre la transición política brasileña. Esto permite desarrollar como salida política posible la relación entre una política de archivo y la práctica de una heterotopía constitucional.

Palabras clave: Archivo. Constitución. La política. 


\section{Referências}

ABRÃO, Paulo; TORELLY, Marcelo D. As dimensões da Justiça de Transição no Brasil, a eficácia da Lei de Anistia e as alternativas para a verdade e a justiça. In: ABRÃO, Paulo et al. Anistia na era da responsabilização: o Brasil em perspectiva internacional e comparada. Brasília, DF: Comissão de Anistia; Ministério da Justiça, 2011. p. 212-248.

AGAMBEN, Giorgio. Homo sacer. O poder soberano e a vida nua I. Tradução de Henrique Burigo. Belo Horizonte: Editora da UFMG, 2007.

BARROSO, Luis Roberto; BARCELLOS, Ana Paula de. O começo da história. A nova interpretação constitucional e o papel dos princípios no direito brasileiro. Revista de Direito Administrativo, Rio de Janeiro, n. 232, p. 141-176, 2003. Disponível em: <http://bibliotecadigital.fgv.br/ojs/index.php/rda/article/viewFile/45690/45068>. Acesso em: 03 jun. 2018.

BERCOVICI, Gilberto. O direito constitucional passa, o direito administrativo permanece: a persistência da estrutura administrativa de 1967. In: SAFATLE, Vladimir; TELES, Edson (Org.). O que resta da ditadura: a exceção brasileira. São Paulo: Boitempo, 2010. p. 77-90.

BONAVIDES, Paulo. A evolução constitucional do Brasil. Estudos Avançados, São Paulo, v. 14, n. 40, p. 155-176, dez. 2000. Disponível em: <http://www.scielo.br/scielo.php?script=sci_arttext\&pi$\mathrm{d}=$ S0103-40142000000300016\&lng=en\&nrm=iso>. Acesso em: 03 jun. 2018.

Curso de direito constitucional. 13. ed. São Paulo: Malheiros, 2003.

BRASIL. Constituição da República Federativa do Brasil de 1988. Brasília, DF, 1988. Disponível em: <http://www.planalto.gov.br/ccivil_03/constituicao/constituicao.htm>. Acesso em: 02 jun. 2018.

. Emenda Constitucional n ${ }^{\circ} 26$, de 27 de novembro de 1985. Convoca Assembléia Nacional Constituinte e dá outras providências. Disponível em: <http://www.planalto.gov.
br/ccivil_03/Constituicao/Emendas/Emc_ anterior1988/emc26-85.htm>. Acesso em: 02 jun. 2018.

. Lei Federal n. 6.683, de 28 de agosto de 1979. Concede anistia e dá outras providências. Disponível em: <http://www.planalto.gov. br/ccivil_03/leis/L6683.htm>. Acesso em: 02 jun. 2018.

CÂMARA, Heloísa Fernandes; MOREIRA, Egon Bockmann. A exceção e a ordem na narrativa constitucional. In: CORRÊA, Murilo Duarte Costa et al. (Org.). O estado de exceção e as formas jurídicas. Ponta Grossa: Editora UEPG, 2017. p. 213-240.

CARVALHO, José Murilo de. Cidadania no Brasil. O longo caminho. Rio de Janeiro: Civilização Brasileira, 2015.

CASTRO, Edgardo. Introdução a Foucault. Tradução de Beatriz de Almeida Magalhães. Belo Horizonte: Autêntica, 2014.

CUNHA, Paulo Ribeiro da. Militares e anistia no Brasil: um dueto desarmônico. In: SAFATLE, Vladimir; TELES, Edson (Org.). O que resta da ditadura: a exceção brasileira. São Paulo: Boitempo, 2010. p. 15-40.

DELEUZE, Gilles. El saber. Curso sobre Foucault. Tomo I. Traducción de Pablo Ires y Sebastián Puente. Buenos Aires: Cactus, 2013.

. Foucault. Paris: Les Éditions de Minuit, 1986.

DERRIDA, Jacques. Força de lei. Tradução de Leyla Perrone-Moisés. São Paulo: Martins Fontes, 2007.

Mal de arquivo. Uma impressão freudiana. Tradução de Cláudia de Moraes Rego. Rio de Janeiro: Relume-Dumará, 2001.

FAGNANI, Eduardo. Ajuste e regressão social. Princípios, São Paulo, v. 4, p. 85-92, 2015. Disponível em: <http://plataformapoliticasocial.com.br/wp-content/uploads/2015/09/ Principios-137-Eduardo.pdf $>$. Acesso em: 03 jun. 2018.

FOUCAULT, Michel. A ordem do discurso. 20. ed. Tradução de Laura Fraga de Almeida Sampaio. São Paulo: Loyola, 2010a. 
. Arqueologia do saber. 7. ed. Tradução de Luiz Felipe Baeta Neves. Rio de Janeiro: Forense Universitária, 2010b.

. Ceci n'est pas une pipe. In: Dits et écrits I (1954-1975). Paris: Quarto/Gallimard, 2001.

O corpo utópico, as heterotopias. Tradução de Salma Tannus Muchail. São Paulo: n-1 Edições, 2013.

HALBWACHS, Maurice. La mémoire collective. Paris: Albin Michel, 1997.

INSTITUTO DE PESQUISA ECONÔMICA APLICADA; FÓRUM BRASILEIRO DE SEGURANÇA PÚBLICA. Atlas da violência 2017. Brasília, DF: Ipea, 2017. Disponível em: <http:/ / www.ipea.gov.br/atlasviolencia/download/2/2017>. Acesso em: 06 jun. 2018.

LE GOFF, Jacques. História e memória. Tradução de Bernardo Leitão et al. 6. ed. Campinas: Editora da Unicamp, 2012.

LYNCH, Christian Edward Cyril; MENDONÇA, José Vicente Santos de. Por uma história constitucional brasileira: uma crítica pontual à doutrina da efetividade. Revista Direito e Práxis, Rio de Janeiro, v. 8, n. 2, p. 974-1007, 2017. Disponível em: <www.scielo.br/pdf/rdp/ v8n2/2179-8966-rdp-8-2-974.pdf>. Acesso em: 06 jun. 2018.

MATOS, Andityas Soares de Moura Costa; SOUZA, Joyce Karina de Sá. Sobrevivências do nazifascismo na teoria jurídica contemporânea e seus reflexos na interpretação judicial brasileira. Revista de Estudos Constitucionais, Hermenêutica e Teoria do Direito, São Leopoldo, v. 9, n. 3, p. 295-310, 2017. Disponível em: <http:/ / revistas.unisinos.br/index.php/RECHTD/article/view/rechtd.2017.93.08>. Acesso em: 06 jun. 2018.

NEGRI, Antonio. O poder constituinte: ensaio sobre as alternativas da modernidade. 2. ed. Tradução de Adriano Pilatti. Rio de Janeiro: Lamparina, 2015.

OST, François. O tempo do direito. Tradução de Maria Fernanda Oliveira. Lisboa: Instituto Piaget, 2001.
PEREIRA, Antony W. Ditadura e repressão. O autoritarismo e o estado de direito no Brasil, no Chile e na Argentina. Tradução de Patrícia de Queiroz Carvalho Zimbres. São Paulo: Paz e Terra, 2010.

PINHEIRO, Paulo Sérgio. Governo democrático, violência e estado (ou não) de direito. In: BETHELL, Leslie (Org.). Brasil: fardo do passado, promessa do futuro. Dez ensaios sobre política e sociedade brasileira. Tradução de Maria Beatriz de Medina. Rio de Janeiro: Civilização Brasileira, 2002. p. 237-269.

Prefácio à edição brasileira. O enigma da legalidade do autoritarismo. In: PEREIRA, Antony W. Ditadura e repressão. O autoritarismo e o estado de direito no Brasil, no Chile e na Argentina. Tradução de Patrícia de Queiroz Carvalho Zimbres. São Paulo: Paz e Terra, 2010. p. 09-14.

RICEEUR, Paul. A memória, a história, o esquecimento. Tradução de Alain François et al. Campinas: Editora da Unicamp, 2007.

SANTOS, Cecília MacDowell. A justiça ao serviço da memória: mobilização jurídica transnacional, direitos humanos e memória da ditadura. In: SANTOS, Cecília MacDowell; TELES, Edson; TELES, Janaina de Almeida (Org.). Desarquivando a ditadura: memória e justiça no Brasil. São Paulo: Hucitec, 2009. v. II. p. 472-495.

SIKKINK, Kathryn; WALLING, Carrie Booth. The impact of human rights trials in Latin America. Journal of Peace Research, Los Angeles, London, New Delhi and Singapore, v. 44, n. 4, p. 427-445, 2007. Disponível em: <http:/ / www. unc.edu/ fbaum/teaching/articles/J-Peace-Research-2007-Sikkink.pdf $>$. Acesso em: 06 jun. 2018.

TELES, Edson. Entre justiça e violência: estado de exceção nas democracias do Brasil e da África do Sul. In: SAFATLE, Vladimir; TELES, Edson (Org.). O que resta da ditadura: a exceção brasileira. São Paulo: Boitempo, 2010. p. 299-318. 